\title{
MEMFASILITASI PEMBELAJARAN BERPUSAT PADA PESERTA DIDIK MELALUI PRAKTIK LESSON STUDY PADA MATA PELAJARAN EKONOMI KELAS X IPS ${ }^{1}$ DI SMAN 10 TERNATE
}

\author{
${ }^{1}$ Rusmini Noh, ${ }^{2}$ Endang Purwati, ${ }^{2}$ Nurmaya Papuangan \\ ${ }^{1}$ SMA Negeri 10 Kota Ternate, Maluku Utara \\ ${ }^{2,3}$ FKIP Universitas Khairun, Ternate Maluku Utara \\ rusmini.noh@gmail.com
}

\begin{abstract}
Objective: This study aims to look at the best practice of lesson study implementation in facilitating participant-centred learning on IPS Economics subjects. Method: This qualitative descriptive study was conducted at SMAN 10 Ternate during AugustNovember 2021 involving subjects as many as 36 students of class X IPS ${ }^{1}$. Data collection uses observation techniques using instruments in the form of observation sheets, recordings of the learning process, and diaries of researchers which are then analyzed qualitatively. Findings: The results of the study showed that the lesson study was able to facilitate learning centred on learners through each implementation at the stages of designing, action, and reflection. Conclusion: Lesson study as a model of improving teacher competence through the study of learning practices contributes positively to teachers and learners in class $X I P S^{1}$ in Economics subjects. Lesson study gives space for teachers to develop their creativity in making changes and improvements. While for learners, lesson study provides space for learning rights to be facilitated to develop their potential. The results of this study are recommendations for improving the quality of learning in high schools in the ternate city, especially in IPS subjects.

Keywords: Lesson Study, Student-Centred Learning.
\end{abstract}

\footnotetext{
ABSTRAK

Tujuan: Penelitian ini bertujuan melihat best-practices implementasi lesson study dalam memfasilitasi pembelajaran yang berpusat pada peserta pada mata pelajaran IPS Ekonomi. Metode: Studi deskriptif kualitatif ini dilakukan di SMAN 10 Ternate selama bulan Agustus-November 2021 dengan melibatkan subyek sebanyak 36 siswa kelas $X$ IPS ${ }^{1}$. Pengumpulan data menggunakan teknik observasi dengan menggunakan instrument berupa lembar observasi, rekaman proses pembelajaran, dan catatan harian peneliti yang kemudian dianalisis secara kualitatif. Temuan: hasil penelitian menunjukkan bahwa lesson study mampu memfasilitasi pembelajaran yang berpusat pada peserta didik melalui setiap implementasi pada tahapan designing, action, and reflection. Kesimpulan: Lesson study sebagai model peningkatan kompetensi guru melalui pengkajian praktik pembelajaran memberi kontribusi positif bagi guru dan peserta didik di kelas $X I P S^{1}$ pada mata pelajaran Ekonomi. Lesson study memberi ruang kepada guru untuk mengembangkan kreatifitasnya dalam melakukan perubahan dan perbaikan. Sementara bagi peserta didik, lesson study memberi ruang hak belajar untuk difasilitasi mengembangkan potensi yang dimilikinya. Hasil penelitian ini menjadi rekomendasi bagi perbaikan kualitas pembelajaran di Sekolah Menengah Atas di Kota Ternate, khususnya pada mata pelajaran IPS.

Kata Kunci: Lesson Study, Pembelajaran Berpusat Pada Peserta Didik.
} 


\section{PENDAHULUAN}

Lesson study sebagai model pengembangan professional guru yang diadopsi dari Jepang yang dinilai menjadi kunci keberhasilan Jepang dalam peningkatan kualitas pendidikannya (Stigler, 1999) telah diimplementasikan pula di berbagai wilayah Indonesia (Mirhaja, 2020), termasuk wilayah Maluku Utara di berbagai sekolah di Kota Ternate (Mas'ud, 2019). Guru adalah agen yang harus mampu mendesain pembelajaran yang interaktif dan melibatkan seluruh peserta didik secara maksimal dalam perolehan pengetahuan (Kurnia, 2017). Guru dalam mengelola pembelajarannya hendaknya senantiasa mengedepankan pengalaman personal peserta didik melalui proses mengamati, menanya, mencoba, menalar, dan mengomunikasikan sebagai upaya untuk membangun kecakapan yang dibutuhkan dalam pembelajaran abad 21. Pembelajaran abad 21 harus dapat mempersiapkan generasi manusia Indonesia menyongsong kemajuan teknologi informasi dan komunikasi dalam kehidupan bermasyarakat. Implikasinya, pembelajaran di sekolah mengharuskan guru dan peserta didik harus melek teknologi dan media komunikasi, dapat melakukan komunikasi yang efektif, berpikir kritis, memecahkan masalah, dan mampu berkolaborasi (syahputra, 2018).

Berdasarkan observasi di kelas X IPS ${ }^{1}$ selama bulan Agustus-November 2021, ditemukan fakta bahwa metode pembelajaran yang diterapkan oleh para guru masih didominasi menggunakan metode konvensional. Guru Ekonomi kadang menerapkan metode diskusi dengan berbantuan media pembelajaran berupa power point untuk melibatkan peserta didik agar aktif, tetapi dalam implementasinya kurang maksimal sehingga pada akhirnya proses pembelajaran kembali didominasi dan dibawah kendali guru (teacher centre learning). Guru masih selalu terjebak pada metode ceramah dan tanya jawab saat pembelajaran dan tidak mencoba menerapkan cara yang berbeda dalam memaksimalkan keterlibatan peserta didik dalam proses pembelajaran (Jayanti, 2014).

Fakta lain di kelas yang menunjukkan bahwa peserta didik tidak dilibatkan oleh guru dalam proses pembelajaran adalah beberapa peserta didik terlihat tidak focus dalam penyelesaian tugas saat dibagikan lembar kerja, beberapa peserta didik lainnya asyik mengobrol tentang hal diluar dari materi yang sedang dibahas saat itu, dan beberapa peserta didik lainnya meminta ijin kepada guru yang bersangkutan keluar kelas (izin kamar kecil).

Pengelolaan pembelajaran yang monoton, keterlibatan peserta didik yang minim, tidak fokusnya peserta didik pada proses pembelajaran merupakan masalahmasalah pembelajaran yang harus segera diatasi agar kualitas pendidikan itu dapat berimbas pada kualitas peserta didik sesuai dengan tuntutan pembelajaran abad 21 . Keberhasilan belajar di abad 21 tidak hanya ditentukan pada seberapa dalam peserta didik memahami dan menguasai konsep materi pelajaran (Larsson, 2017), tetapi juga bagaimana dalam proses pembelajaran itu mampu melatihkan kecakapan/keterampilan yang mempersiapkan peserta didik menghadapi tantangan hidup pada masanya.

Oleh karenanya, salah satu upaya yang dapat dilakukan untuk memfasilitasi melibatkan peserta didik secara maksimal dalam proses pembelajaran adalah dengan menerapkan lesson study. Lesson study merupakan hal baru bagi guru IPS Ekonomi di SMAN 10 Ternate, oleh karena itu penelitian ini dibuat untuk 
mendeskripsikan implementasi lesson study bagi guru IPS Ekonomi untuk memfasilitasi pembelajaran yang berpusat pada peserta didik (student centre learning).

Lesson study merupakan kegiatan pengkajian praktik pembelajaran yang dilakukan secara kolaboratif dan berkelanjutan berlandaskan prinsip kolegialitas dan mutual learning untuk membangun komunitas belajar (Hendayana, 2007). Menurut (Pang, 2013), Lesson Study Jepang telah diperluas menjadi Learning Study for learning community yaitu sebuah model yang menjadi ide untuk menyatukan variasi dan pembelajaran. Sedang (Hurd \& Licciardo Musso, 2004) mendefinisikan, lesson study is a cycle of professional development focused on teachers planning, observing, and revising "research lesson".

Lesson study secara lebih lengkap dapat diartikan sebagai suatu proses kolaboratif dari sekelompok guru untuk secara bersama-sama mengidentifikasi masalah pembelajaran yang dialami oleh guru dan merencanakan kegiatan pembelajaran yang diprediksikan dapat memberi bantuan kepada peserta didik untuk mengatasi kesulitan belajarnya. Hal ini dilakukan pada tahapan perencanaan (designing). Diskusi pada perencanaan ini dapat melibatkan siapapun yang memiliki kepedulian untuk mengkaji bersama langkah antisipasi yang dapat dilakukan oleh guru model di kelasnya tersebut. Filosofi keterbukaan dalam lesson study dapat memberi ruang kepada guru untuk saling menginspirasi, sebab kelas tidak lagi menjadi ruang pribadi guru dalam mengajar, tetapi menjadi ruang observasi untuk mengidentifikasi persoalan pembelajaran dan menemukan ide solutif (Purwati \& Sangaji, 2020).

Pada proses pelaksanaan (action) pembelajaran yang dilakukan oleh guru model, para pihak yang melibatkan diri sejak awal perencanaan itu dapat menjadi observer pembelajaran di kelas tersebut. Pengamat dapat menggunakan alat rekam baik visual maupun audio untuk mengamati perilaku belajar peserta didik. Tim yang dilibatkan adalah guru/dosen model dan observer yang bisa saja terdiri 4-10 orang. Focus pengamatan para observer adalah bagaimana peserta didik belajar.

Pada tahapan refleksi (reflection), memperbaiki perencanaan pembelajaran berdasarkan pada hasil refleksi (Redisign) dan membagi (menyebarluaskan) pengalaman dan temuan dari hasil evaluasi tersebut kepada guru lain. Lesson study merupakan salah satu alternatif untuk memperbaiki dan meningkatkan kualitas pembelajaran di kelas, dimana fokus dari pelaksanaan lesson study bukanlah pada guru, namun pada kemajuan belajar peserta didik.

\section{METODE}

Penelitian ini merupakan penelitian deskriptif kualitatif yang digunakan untuk mendapatkan gambaran bagaimana penerapan lesson study ini dapat memfasilitasi peserta didik dalam proses pembelajaran mata pelajaran Ekonomi di kelas X IPS-1 di SMAN 10 Kota Ternate. Subjek penelitian adalah peserta didik yang berjumlah 36 orang. Tim lesson study terdiri atas guru model 1 orang, guru pengamat 3 orang ( 1 guru mapel Ekonomi dan 2 guru mapel Geografi), pengawas 1 orang (coordinator pengawas Prov. Malut), dan dosen 2 orang.

Teknik pengumpulan data dilakukan menggunakan instrumen penelitian yang berupa lembar observasi, rekaman proses pembelajaran, dan catatan peneliti. Data 
dalam penelitian ini merupakan data kualitatif berupa catatan harian peneliti yang menggambarkan proses pembelajaran yang berlangsung dan tanggapan observer mengenai proses pembelajaran tersebut. Data kualitatif juga mencakup kendalakendala yang dijumpai guru model dalam proses desain pembelajaran, pengeloaan pembelajaran saat buka kelas untuk diamati, tanggapan observer terhadap proses pembelajaran dan kendala-kendala yang ditemui dalam proses pembelajaran dianalisis secara deskriptif-kualitatif.

Tahapan-tahapan pelaksanaan lesson study meliputi;

1. Perencanaan/Designing

Pada tahap ini tim lesson study yang terdiri dari kelompok guru-guru IPS (Ekonomi) dan dosen bersama-sama merancang dan mendesain perangkat pembelajaran meliputi rencana pelaksanaan pembelajaran (RPP) untuk satu pertemuan, lembar kerja peserta didik (LKPD), penyiapan media dan bahan ajar, skenario pembelajaran, dan penilaian.

2. Pelaksanaan/Action

Pada tahap ini terdapat dua kegiatan utama yaitu; kegiatan pelaksanaan pembelajaran oleh guru model dan kegiatan pengamatan atau observasi yang dilakukan oleh guru mitra lain dan dosen.

3. Refleksi/Reflection

Pada tahap ini, tim lesson study berkumpul dan mengevaluasi proses dan mendiskusikan hasil pembelajaran yang telah dilaksanakan serta meredesign kembali scenario pembelajaran berdasarkan temuan dan masukan dari para observer untuk diimplementasikan pada pembelajaran pertemuan berikutnya.

\section{HASIL DAN PEMBAHASAN}

Implementasi lesson study dalam pembelajaran Ekonomi diawali pada tahap perencanaan dengan berkolaborasi bersama guru IPS lainnya. Kolaborasi dalam mendesain pembelajaran ini pun memberi pengalaman baru bagi guru model dalam mempersiapkan pembelajarannya (Endang \& Sangaji, 2020). Hal baik yang diperoleh guru model melalui kolaborasi tersebut yakni memperoleh masukan berupa gagasan baru untuk pemilihan model belajar yang relevan dengan tujuan pembelajaran pada kompetensi dasar yang sedang dipelajari, lembar kerja yang dapat memaksimalkan keterlibatan peserta didik, pemanfaatan media ajar yang bervariasi, dan teknik penilaian yang obyektif yang semuanya itu dimaksudkan untuk melibatkan peserta didik aktif dalam proses pembelajaran dan berimbas pada peningkatan hasil belajarnya. Lembar kerja peserta didik menjadi salah satu komponen penting dalam perangkat pembelajaran untuk memfasilitasi peserta didik aktif dalam proses pembelajaran (Sri Utami, 2016). LKPD yang didesain pada materi "Inti masalah ekonomi", diaplikasikan pada lembar kerja media kertas manila, agar dalam proses pembelajaran terbangun focus konsentrasi pada komunikasi dan kolaborasi yang menjadi masalah utama di kelas X IPS ${ }^{1}$ tersebut.

Berdasarkan hasil diskusi refleksi dan catatan hasil pengamatan para observer memperlhatkan bahwa, media LKPD yang diaplikasikan dalam media kertas manila tersebut cukup melibatkan seluruh anggota kelompok peserta didik dalam diskusi penyelesaian tugas kelompok. Media ini menyatukan focus dan konsentrasi dari seluruh anggota kelompok. Padahal menurut guru model yang menjadi guru 
pengajar di kelas tersebut, saat peserta didik dibuatkan kelompok untuk menyelesaikan suatu tugas, hanya 2 orang peserta yang maksimal terlibat dalam penyelesaian tugas tersebut. Tetapi, pada saat tugas diaplikasikan pada media yang sederhana yang berbeda dari biasanya, peserta memperlihatkan antusias mengerjakan tugas dan komunikasi antar peserta terjadi tanpa guru instruksikan. Respon peserta didik dalam berinteraksi dengan teman kelompok dan media dapat dilihat pada gambar 1 di bawah ini:

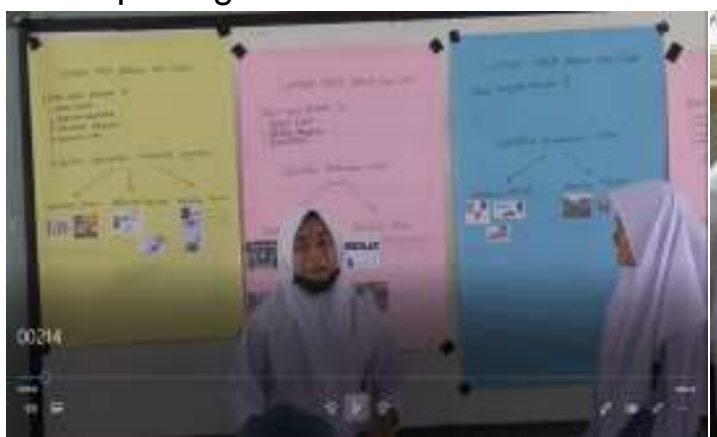

(a)

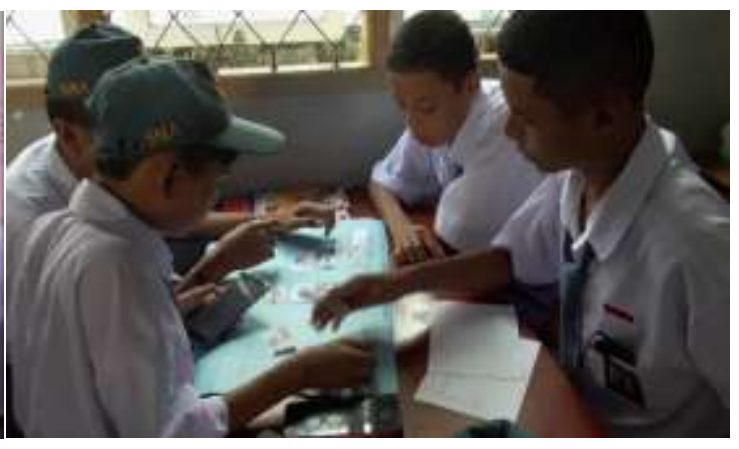

(b)

Gambar 1: (a) aktivitas peserta didik dalam kelompok diskusi (b) aktivitas presentasi hasil penyelesaian LKPD kelompok.

Pada tahapan buka kelas, para observer focus mengamati aktivitas belajar peserta didik. Guru model mengelola pembelajaran sesuai dengan skenario yang sudah disusun pada tahapan perencanaan/designing. Kesan refleksi pengajaran yang disampaikan oleh guru model setelah buka kelas, mengungkapkan bahwa penerapan lesson study menghemat energi dan waktu guru model dalam mengontrol peserta didik di kelasnya. Keterlibatan peserta didik dalam pembelajaran lebih responsif dibandingkan sebelumnya. Peserta didik secara natural memanfaatkan seluruh sumber belajar yang tersedia untuk menyelesaikan tugas dalam LKPD tanpa instruksi intens dari guru model.

Hasil catatan pengamatan dan temuan observer dalam diskusi refleksi dengan guru model, mengungkapkan bahwa sebagian besar peserta didik dapat memahami konsep yang dibahas pada pertemuan tersebut. Beberapa anggota kelompok yang tadinya tidak konsentrasi dalam pembelajaran (terlihat mengantuk dan lesu) pada awal pembelajaran, tetapi saat LKPD dibagikan dengan menggunakan media kertas manila, mulai tertarik untuk membaca instruksi dalam lembar kerja tersebut. Berikut beberapa hasil dari lembar kerja yang diselesaikan secara kolaborasi dalam menentukan berbagai macam jenis kebutuhan berdasarkan klasifikasinya. 

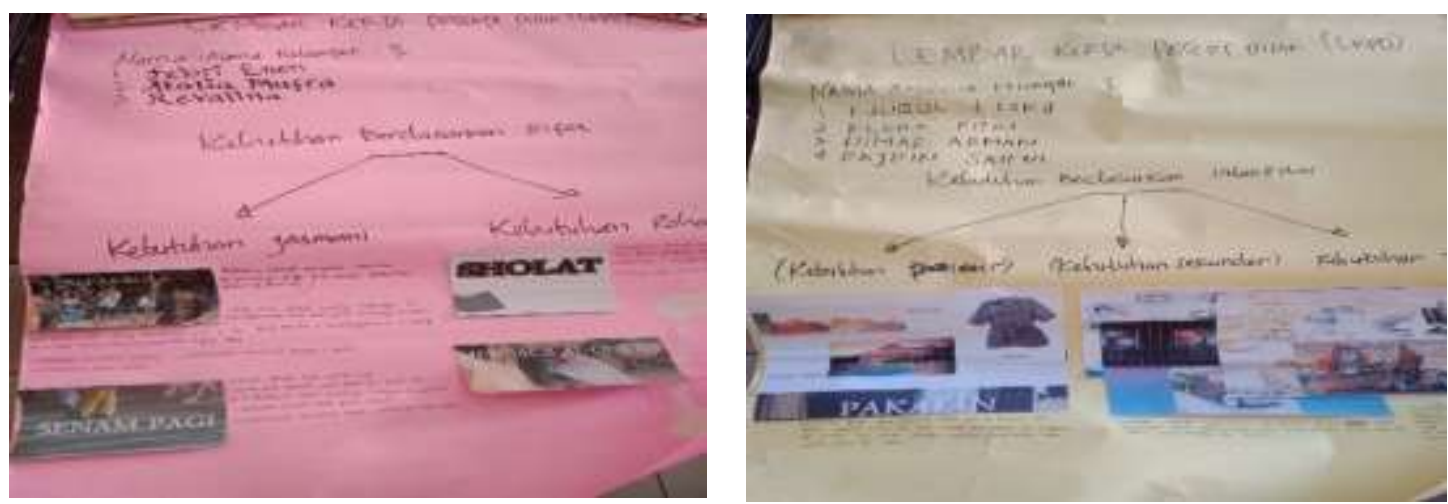

Gambar 2: Hasil kerja yang diselesaikan dengan melibatkan semua anggota kelompok.

Beberapa temuan dan masukan dari para observer dari guru mitra dan dosen menjadi redesign untuk pertemuan selanjutnya. Perbaikan pada aspek perencanaan yakni, lembar kerja yang dirancang dibuat dalam narasi kasus tentang inti masalah ekonomi yang sifatnya kontekstual, tidak berdasarkan buku siswa semata. Pada aspek pengelolaan kelas, guru model harus sering berlatih untuk mengurangi instruksi dalam pembelajaran. Baiknya untuk membantu menertibkan kelas sebelum pembelajaran dimulai, dibuat kesepakatan aturan/tata tertib dengan peserta didik sehingga aturan itu bersumber dari kesadaran peserta didik. Untuk beberapa peserta didik yang terlihat belum secara maksimal terlibat dalam proses pembelajaran, baiknya dikelompokkan bersama peserta didik lain yang dapat memberinya bantuan dalam proses belajarnya (tutor sebaya).

Pada saat diskusi, ditemukan pola dialog antar peserta didik dalam diskusi. Interaksi dalam dialog peserta didik yang membahas terkait materi yang sedang dibahas berupa dialog bertanya, menjawab, dan menguatkan temuan informasi dari berbagai sumber informasi. Catatan pola dialog diskusi tersebut dapat dilihat pada gambar berikut;

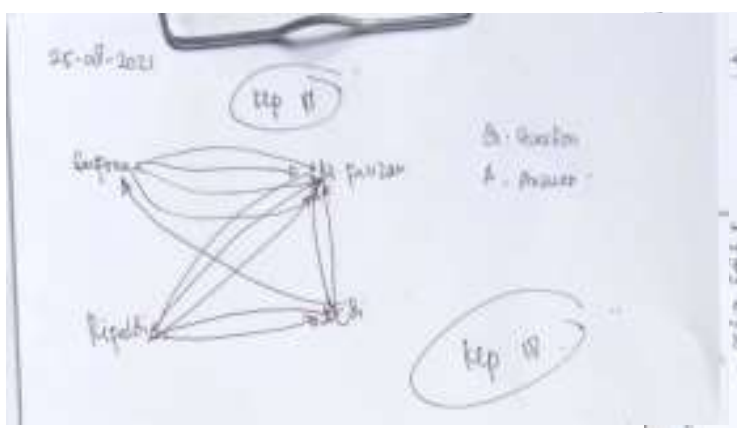

(a)

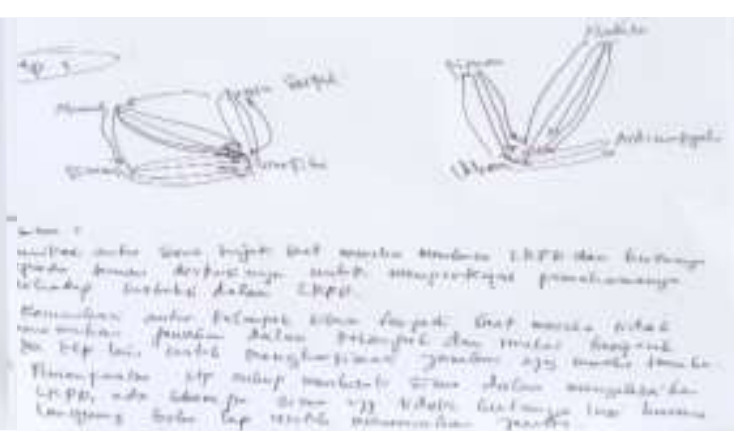

(b)

Gambar 3: (a) Pola dialog kelompok III dalam diskusi (b) pola dialog kelompok 1 dan IV yang tercatat dalam spider web discussion.

Gambar tersebut menunjukkan pola berkomunikasi antar peserta dalam menyelesaikan LKPD. Garis komunikasi yang banyak mengarah pada satu atau dua peserta menunjukkan bahwa, kepercayaan peserta untuk bertanya dan menemukan jawaban dari soal yang harus diselesaikan itu mulai terbangun. Tidak lagi 
menempatkan gurunya sebagai sumber informasi utama. Sehingga pola diskusi seperti ini mulai mengurangi dominasi guru dalam mengarahkan proses diskusi. Peserta membangun kepercayaan dirinya untuk mengomunikasikan apa yang dipikirkannya kepada teman sekelompoknya. Mengamati pola interaksi komunikasi peserta dalam proses pembelajaran ini disebut Spider Web Discussion (SWD). Spider web discussion merupakan cara yang dapat digunakan oleh guru model dan pengamat untuk mengamati dan melihat bagaimana peserta didik berdiskusi secara kolaboratif dan menjadikan proses belajar tersebut bermakna, sehingga peserta didik dapat ditempatkan sebagai subyek dalam proses pembelajaran dan bukan menjadi obyek.

Sementara itu untuk melihat bagaimana tanggapan peserta didik terhadap proses pembelajaran hari itu, guru model meminta seluruh peserta untuk menuliskan refleksinya. Ada banyak tanggapan baik yang disampaikan oleh peserta secara tertulis. Catatan refleksi pembelajaran peserta dapat dilihat pada gambar 4 di bawah.

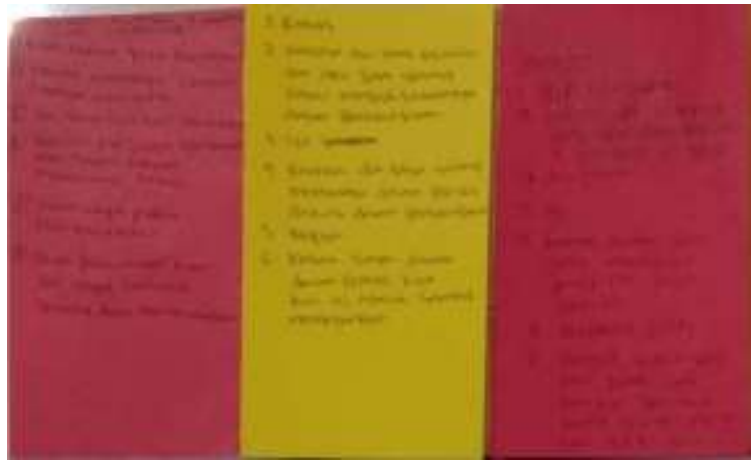

(a)

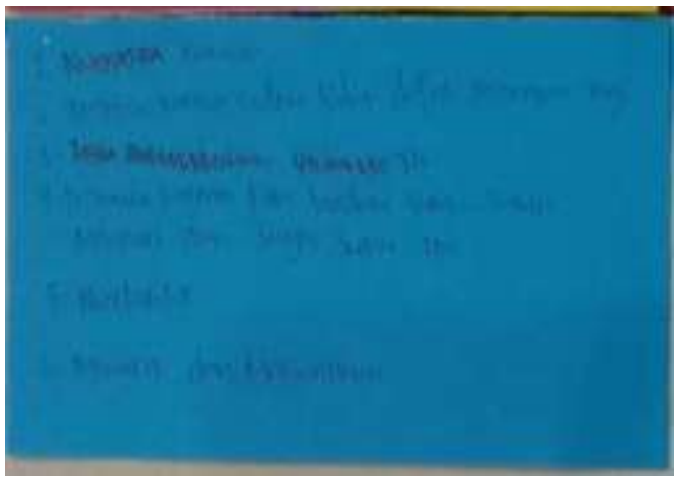

(b)

Gambar 4: (a) Refleksi peserta didik saat diberi kebebasan untuk memilih sendiri teman belajarnya (b) Refleksi peserta didik yang merasa terbantukan dalam diskusi kelompok.

\section{PENUTUP}

Lesson study, sebagai model peningkatan kompetensi guru melalui pengkajian praktik pembelajaran sangat banyak memberi kontribusi positif bagi guru dan peserta didik di kelas X IPS ${ }^{1}$ pada mata pelajaran Ekonomi. Lesson study memberi ruang kepada guru untuk mengembangkan kreatifitasnya dalam melakukan perubahan dan perbaikan. Sementara bagi peserta didi, lesson study memberi ruang hak belajar untuk difasilitasi mengembangkan potensi yang dimilikinya. Praktik baik yang diperoleh dari penelitian ini perlu ditindaklanjuti agar gerakan lesson study ini menjadi kebijakan di SMAN 10 Kota Ternate dan menjadi rekomendasi bagi Dinas Pendidikan dan Kebudayaan Prov. Maluku Utara untuk memfasilitasi penerapan lesson study di persekolahan.

\section{Daftar Pustaka}

Endang, P., \& Sangaji, K. (2020). Kolaborasi Guru dalam Mendesain Pembelajaran Melalui Praktik Lesson Study for Learning Community di SMK Pembangunan Ternate. Jurnal IImiah Wahan Pendidikan, 35-40. 
Hendayana, S. d. ( 2007). Lesson Study Suatu Strategi Untuk Meningkatkan keprofesionalan Pendidik. Bandung: FPMIPA UPI dan JICA,.

Jayanti, N. K. (2014). Pengaruh model pembelajaran Heuristik-V berbantuan peta konsep terhadap pemahaman konsep IPA siswa kelas V. E-Jurnal MIMBAR PGSD Universitas Pendidikan Gansha, 21-25.

Kurnia, N. D. (2017). The Implementation of Find Someone Who and Two Stay Two Stray Models to Improve Students' Self-Efficacy And Social Studies Learning Outcomes. IOSR Journal of Research \& Method in Education, 07(03), 6670. doi:10.9790/7388-0703036670

Larsson, K. (2017). Understanding and teaching critical thinking-A new approach. International Journal of Educational Research, 32-42.

Mas'ud, A. H. (2019). The development of lesson design to improve collaboration activities and scientific work. AIP Conference Proceedings, (p. 2194).

Mirhaja, F. J. (2020). Tokkatsu:Initiating Students' Collaborative Activities in Lesson Study Piloting School. Jurnal Pendidikan Progresif, 10(1), 63-72. doi:10.23960/jpp.v10.i1.202008

Pang, M. a. (2013). Learning study: helping teachers to use theory, develop professionally, and produce new knowledge to be shared. Instructional Science, 589-606.

Purwati, E., \& Sangaji, K. (2020). Kolaborasi Guru dalam Mendesain Pembelajaran Melalui Praktik Lessn Study for Learning Community di SMK Pembangunan Ternate. Jurnal IImiah Wahan Pendidikan, 35-40. doi:10.5281/zenodo.3627414

Sri Utami, W. S.-,. (2016). The Effectiveness of Geography Student Worksheet to Develop Learning Experiences for High School Students. Journal of Education and Learning, 315. Retrieved from https://doi.org/10.5539/jel.v5n3p315

Stigler, J. W. (1999). The teaching gap: Best ideas from the world's teachers for improving in the classroom. New York: The Free Press.

syahputra, E. (2018). Pembelajaran Abad 21 dan Penerapannya Di Indonesia. Seminar Nasional SAINS, TEKNOLOGI, HUMANIORA, DAN PENDIDIKAN (pp. 1276-1283). Medan: SINASTEKMAPAN. 